\title{
Experimental and Theoretical Investigations of a Triple Vortex Combustor with Spatial Arc
}

\author{
Igor Matveev ${ }^{*}$, Svetlana Matveeva+ and Evgeniy Kirchuk ${ }^{\mathrm{a}}$ \\ Applied Plasma Technologies, McLean, Virginia, 22101 \\ Serhiy Serbin ${ }^{\dagger}$ \\ National University of Shipbuilding, Mikolayiv, 54025, Ukraine
}

\begin{abstract}
Theoretical and experimental investigations of working processes in a triple vortex combustor with spatial arc have been conducted. Selected concept of portable triple vortex plasma assisted combustor can provide higher performance, wider turn down ratios, more efficient propellants utilization, decrease combustor and engine weight, demonstrate potential fuel flexibility, satisfy major gravimetric and volumetric density requirements. Obtained results and recommendations can be used for triple vortex combustor operation modes and geometry optimization, prospective combustors for propulsion and power generation design and engineering.
\end{abstract}

\section{Introduction}

$\mathrm{T}$ HERE are several major obstacles to overcome on the way of the prospective combustor development as: combustion efficiency, emission of toxic components, combustor's aerodynamic resistance, heightened sensibility of the working processes to inlet temperature and velocity irregularities, fuel/air ratio precise regulation, complicated design and high production cost, necessity in portable, lightweight and efficient subsystems as ignition, fuel feeding, flame control ${ }^{1-3}$.

There is an opportunity to improve dramatically the combustor's parameters (performance, fuel consumption, weight, size, cost, reliability, toxicity, etc.) by employing several innovations. They are as follows:

- triple reverse vortex flow ${ }^{4-8}$, which utilizes high circumferential flows to decrease the combustor size, provides cold walls and eliminates compressed air for their cooling, replaces expensive high temperature alloys for the combustor fabrication on thin carbon steel, dramatically simplifies combustor design and swirlers due to outstanding mixing abilities of the reverse vortex, significantly widens flammability limits, provides more options for fuel selection;

- spatial $\operatorname{arc}^{4,7}$ for energy efficient and reliable ignition at any conditions and continuous flame control - a real break through solution, which employs the combustor walls like electrodes for spatial, rotating, high voltage and low current arc (several $\mathrm{kV}$ and tens of milliamps) for reliable ignition, flame control, flammability limits widening, ignition delay time reduction (important for alternative fuels) and combustion enhancement.

Applied Plasma Technologies (APT) has an expertise in research and development of small scale reverse flow combustors for gas turbines and variety of portable plasma generators, plasma enhanced fuel reformers ${ }^{4,5,7,9}$. Recently engineered the basic reverse vortex "Tornado" combustor with spatial arc has been investigated. It has ID $=145 \mathrm{~mm}$, length $240 \mathrm{~mm}$, volume about 4 liters and was designed for atmospheric pressure operation and experiments with different fuels (liquid and gaseous) and reagents, as well as for fuel feeding solutions optimization. For the process visualization, the main wall could be fabricated from quartz. Preliminary combustor tests showed that the reverse vortex starts working at a very low pressure differential (about $50 \mathrm{~mm}$ of water column), which means low chamber resistance, as well as good protection of the chamber walls. Even with an output gases

\footnotetext{
* President \&CEO, 1729 Court Petit, McLean, VA 22101

+ Chief Designer, 1729 Court Petit, McLean, VA 22101

${ }^{a}$ Research Engineer, 1729 Court Petit, McLean, VA 22101

${ }^{\dagger}$ Professor, Dept. of Turbine Units, 9 Geroev Stalingrada Ave., Mykolayiv, Ukraine, 54025
} 
temperature of about $1200{ }^{\circ} \mathrm{C}$, the walls and nozzle temperature did not exceed $340{ }^{\circ} \mathrm{C}$. This means that no cooling is required. The reverse vortex mixes reagents very well; due to aerodynamics their residence time is much higher than in other vortex chambers, and the outlet nozzle could be up to $90 \%$ of the chamber ID (from 45 to $130 \mathrm{~mm}$. The spatial arc starts working from a pressure differential of about $15 \mathrm{~mm}$ of $\mathrm{H}_{2} \mathrm{O}$ and a power level starting from 40 $\mathrm{W}$, which allows ionize reagents without visible electrode erosion. This schematic was successfully scaled from ID $=7$ to $145 \mathrm{~mm}$ and air flow rate from 0.01 to 25 grams per second.

Some CFD calculations have been done for better understanding of the reverse vortex flow ${ }^{6,8,9,10}$. Using both the

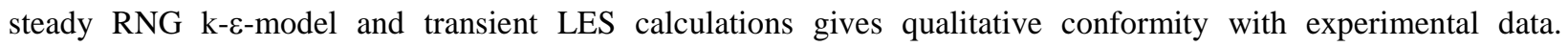
Preliminary calculations have shown that with air velocity changing in tangential channels of the vortex generator from 40 up to $80 \mathrm{~m} / \mathrm{s}$ (without special diffuser in reverse vortex combustor inlet) total pressure losses under fuel burning conditions come to 3.0-9.8\%. This value is comparable to pressure losses in the aircraft combustors equipped with diffuser for reduction of air velocity after compressor.

To date engineering solutions have essential imperfection consisting in generations of a spatial electric arc in the region of the combustor exit nozzle. Therefore influence of non-equilibrium plasma on a high reactionary fuel-air mixture formation in the combustor is considerably diminished. Spatial arc generation in the combustor bottom region where the hydrocarbon fuel is injected is fundamentally novel. That will demand the air flow partition on two streams: primary and plasma-forming, which enters the triple vortex combustor through the own vortex generators. In this case there is a capability to utilize high circumferential swirled air flows to decrease combustor size with high burning efficiency and small toxic ingredients emission due to the plasma intensification. The complex flow structure in such triple vortex combustor requires detailed numerical simulation of reacting swirling streams interaction and corresponding experimental and theoretical investigations of the geometry and operation parameters.

\section{Triple Vortex Combustor Design}

For the purpose of immediate effect of non-equilibrium plasma on the processes of combustion-mixture preparation a small-sized triple vortex combustor with internal diameter $73 \mathrm{~mm}$ and length $150 \mathrm{~mm}$ was designed and manufactured (Fig. 1). For this design a spatial arc initiation occurs in the bottom area. Primary and plasmafeedstock air are injected separately through the tangential channels of vortex generators located near the exit nozzle and the bottom part accordingly. In this case excitation of swirled spatial arc in a fuel feeding zone ensures
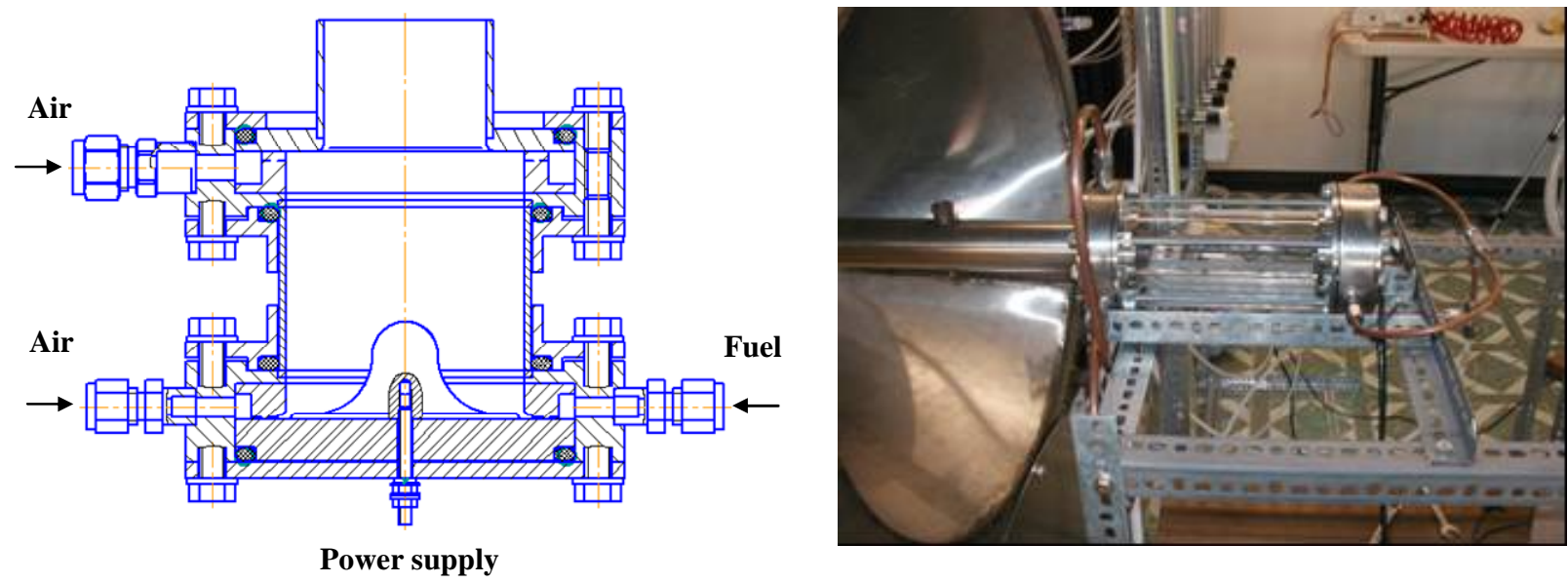

Figure 1. Triple vortex combustor with spatial arc.

conditions for thermal, kinetic and turbulent influence of plasma discharge on the processes of mixing, ignition and burning.

The following modes of the gaseous fuel injection into the combustor were provided: a) together with plasma feedstock air; b) through a plasma pilot installed at the bottom plate centre; c) by a central atomizer; d) through four symmetrically located nozzles.

Excitation of spatial arc was provided by a custom designed high-voltage (up to $30 \mathrm{\kappa V}$ ) power supply having a capability for power control from 10 to $200 \mathrm{~W}$. Fig. 2 illustrates spatial arc without and with propane injection 


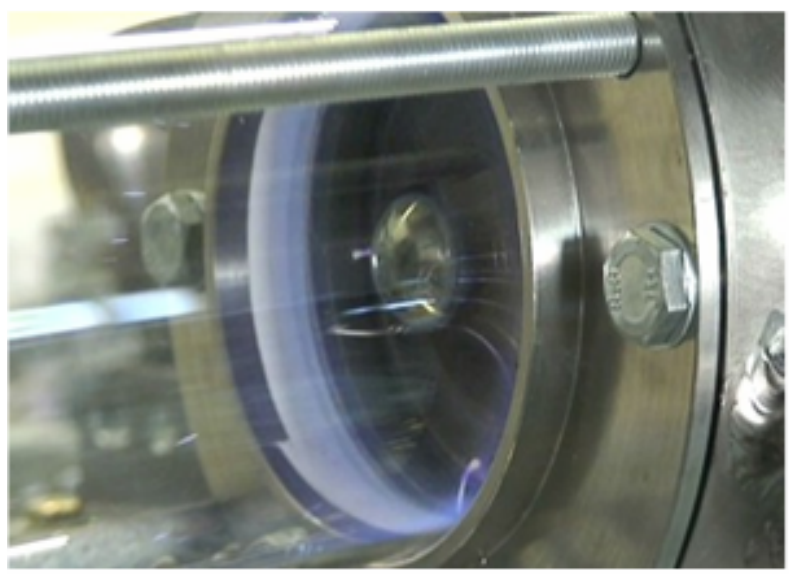

a)

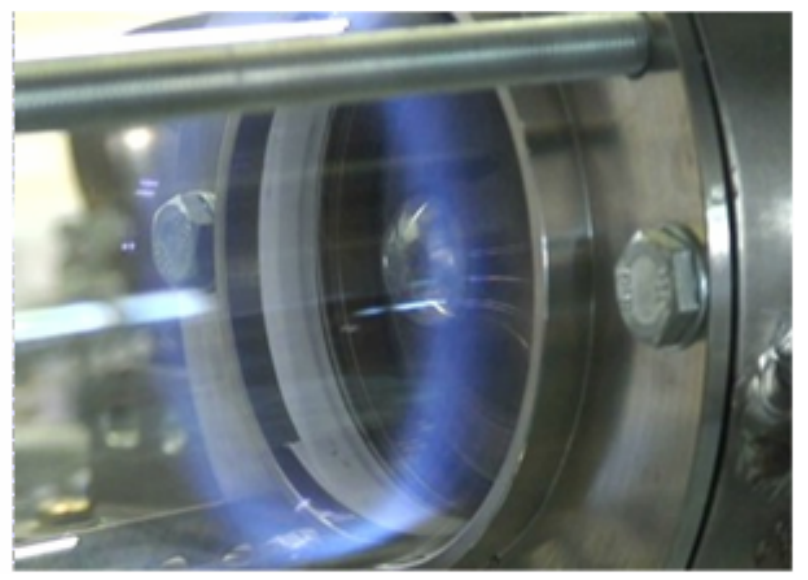

b)

Figure 2. Working process visualization in a triple vortex combustor with spatial arc: a) - without fuel injection, b) - with fuel injection.

through the air inlet. Because of low power arc no erosion of electrodes was observed (central cathode and casing) even after several hours of operation.

During the triple vortex combustor tests a special exhaust tube with $600 \mathrm{~mm}$ length was adjusted to the exit nozzle to avoid air injection from the atmosphere and combustion products dilution. The sampling device with 9 averaging holes was mounted in the cross-section of this tube at the distance of $300 \mathrm{~mm}$ downstream the exit nozzle.

\section{Mathematical Modeling}

For modeling of physical and chemical processes inside the triple vortex combustors with plasma torches and spatial arc a generalized method based on numerical solution of the combined conservation and transport equations for multi-component chemically reactive turbulent system was employed ${ }^{9-14}$. This method provides a procedure of numerical integration of the differential equations, which describe reacting viscous gas flows. A 3D model of stationary and non-stationary reacting flows has been utilized which allows to predict plasma-chemical influence and optimize parameters taking into consideration mixing, turbulence, radiation and combustion features. The RNG $k-\varepsilon$ - turbulence model was chosen as it is more responsive to the effects of rapid strain and streamlines curvature.

Modeling of physical and chemical processes in triple vortex combustor is based on solution of the differential equations of mass, impulse and energy conservation for the multi-component, turbulent, chemically reacting system in the following way:

- equation for conservation of mass

$$
\frac{\partial \rho}{\partial t}+\nabla \cdot(\rho \vec{v})=S_{m}
$$

- equation for conservation of momentum

$$
\frac{\partial}{\partial t}(\rho \vec{v})+\nabla \cdot(\rho \vec{v} \vec{v})=-\nabla p+\nabla \cdot\left(\tau_{s t}\right)+\rho \vec{g}+\vec{F}
$$

- transport equation for chemical species

$$
\frac{\partial}{\partial t}\left(\rho Y_{i}\right)+\nabla\left(\rho \vec{v} Y_{i}\right)=-\nabla \cdot \vec{J}_{i}+R_{i}+S_{i},
$$

- equation for conservation of energy 


$$
\frac{\partial}{\partial t}(\rho E)+\nabla \cdot(\vec{v}(\rho E+p))=-\nabla \cdot \vec{J}_{i}+S_{h},
$$

- transport equations for the RNG $k$ - $\varepsilon$-model

$$
\begin{gathered}
\frac{\partial}{\partial t}(\rho k)+\frac{\partial}{\partial x_{i}}\left(\rho k u_{i}\right)=\frac{\partial}{\partial x_{j}}\left(\alpha_{k} \mu_{e f f} \frac{\partial k}{\partial x_{j}}\right)+G_{k}+G_{b}-\rho \varepsilon-Y_{M}+S_{k}, \\
\frac{\partial}{\partial t}(\rho \varepsilon)+\frac{\partial}{\partial x_{i}}\left(\rho \varepsilon u_{i}\right)=\frac{\partial}{\partial x_{j}}\left(\alpha_{\varepsilon} \mu_{e f f} \frac{\partial \varepsilon}{\partial x_{j}}\right)+C_{1 \varepsilon} \frac{\varepsilon}{k}\left(G_{k}+C_{3 \varepsilon} G_{b}\right)-C_{2 \varepsilon} \rho \frac{\varepsilon^{2}}{k}-R_{\varepsilon}+S_{\varepsilon}, \\
\mu_{t 0}=C_{\mu} \rho k^{2} / \varepsilon, \mu_{t}=\mu_{t 0} f\left(\alpha_{s}, \Omega, \frac{k}{\varepsilon}\right), R_{\varepsilon}=\frac{C_{\mu} \rho \eta^{3}\left(1-\eta / \eta_{0}\right)}{1+\beta \eta^{3}} \frac{\varepsilon^{2}}{k}, \eta=S k / \varepsilon
\end{gathered}
$$

The above mentioned equations are written down in the vectorial form for which operator

$$
\nabla=i \frac{\partial}{\partial x}+j \frac{\partial}{\partial y}+k \frac{\partial}{\partial z}
$$

and the fluid velocity vector

$$
u=u(x, y, z, t) i+v(x, y, z, t) j+w(x, y, z, t) k,
$$

where $i, j, k$ are the unit vectors in the $x, y, z$ directions.

In these equations $t$ is the time; $\rho$ is the mass density of the mixture; $S_{m}$ is the mass added to the continuous phase from the dispersed second phase and any user-defined sources; $p$ is the fluid pressure; $\tau_{s t}$ is the stress tensor; $\rho \vec{g}$ and $\vec{F}$ are the gravitational body force and external body forces; $Y_{i}, R_{i}$ are the mass fraction and net rate of production of species $i$ by chemical reaction; $\vec{J}_{i}$ is the diffusion flux of species $i ; S_{i}$ is the rate of creation by addition from the dispersed phase plus any another sources; $S_{h}$ is the heat of chemical reaction and any other volumetric heat sources; $k$ and $\varepsilon$ are the turbulent kinetic energy and the rate of its dissipation; $\mu_{e f f}$ is the effective viscosity; $G_{k}$ represents generation of a turbulence kinetic energy due to the mean velocity gradients; $G_{b}$ is the generation of turbulence kinetic energy due to buoyancy; $Y_{M}$ represents the contribution of the fluctuating dilatation in compressible turbulence to the overall dissipation rate; the quantities $\alpha_{k}$ and $\alpha_{\varepsilon}$ are the inverse effective Prandtl numbers for $k$ and $\varepsilon$, respectively; $S_{k}$ and $S_{\varepsilon}$ are user-defined source terms; $C_{1 \varepsilon}, C_{2 \varepsilon}, C_{3 \varepsilon}$ are the constants of turbulence model; $\mu_{t 0}$ is the value of turbulent viscosity calculated without the swirl modification; $\Omega$ is the characteristic swirl number; $\alpha_{s}$ is the swirl constant.

For triple vortex combustion calculation three basic combustion models have been used:

1. Eddy-dissipation model: reaction rates are assumed to be controlled by the turbulence, so expensive Arrhenius chemical kinetic calculations can be avoided

2. Combination of laminar finite-rate and eddy-dissipation models: reaction rates are determined by Arrhenius expressions and parameters of turbulence.

3. Eddy-dissipation-concept (EDC) model: detailed Arrhenius chemical kinetic can be incorporated in flames with turbulent fluctuations.

Note, that the first model is computationally cheap, but it doesn't give realistic results in chemically controlled systems. Detailed chemical kinetic calculations are computationally very expensive, and reasonable compromise is required with chemical mechanisms selection.

In eddy-dissipation model the net rate of production of species $i$ due to reaction $r$ is given by the smaller (i.e., limiting value) of the two expressions: 


$$
R_{i, r}=v_{i, r}^{\prime} M_{w, i} A B \rho \frac{\varepsilon}{k} \frac{\sum_{P} Y_{R}}{\sum_{j}^{N} v_{j, r}^{\prime \prime} M_{w, j}} \text { and } R_{i, r}=v_{i, r}^{\prime} M_{w, i} A \rho \frac{\varepsilon}{k} \min \left(\frac{Y_{R}}{v_{R, r}^{\prime} M_{w, R}}\right)
$$

Note, that reaction general form is $\sum_{i=1}^{N} v_{i, r}^{\prime} \mathrm{M}_{i} \underset{k_{b, r}}{k_{f, r}} \sum_{i=1}^{N} v_{i, r}^{\prime \prime} \mathrm{M}_{i}$.

In finite-rate/eddy-dissipation model the net reaction rate is taken as the minimum of eddy-dissipation and finiterate indexes. In practice, the Arrhenius rate acts as a kinetic "switch", preventing reaction before the flame holder. Once the flame is ignited, the eddy-dissipation rate is generally smaller than the Arrhenius rate, and reactions are mixing-limited.

The net source of chemical species $i$ due to reaction

$$
R_{i}=M_{w, i} \sum_{r=1}^{N_{R}} R_{i, r}
$$

The forward and backward rate constants

$$
k_{f, r}=A_{r} T^{\beta_{r}} e^{-E_{r} / R T} \text { and } k_{b, r}=\frac{k_{f, r}}{K_{r}} .
$$

The molar rate of creation/destruction of species $i$ in reaction $r$

$$
R_{i, j}=\Gamma\left(v_{i, r}^{\prime \prime}-v_{i, r}^{\prime}\right) \cdot\left(k_{f, r} \prod_{j=1}^{N}\left[C_{j, r}\right]^{\eta_{j, r}^{\prime}}-k_{b, r} \prod_{j=1}^{N}\left[C_{j, r}\right]^{v_{j, r}^{\prime \prime}}\right) .
$$

Eddy-dissipation-concept model assumes that reaction occurs in small turbulent structures, called fine scales. Species react in the fine structures over a timescale. Reactions proceed over the time scale, governed by Arrhenius rates and are integrated numerically using ISAT algorithm. So to calculate the net source of species $i$ by chemical reaction it is necessary to find the volume fine scale and time scale.

The length fraction and time scales are

$$
\xi^{*}=C_{\xi}\left(\frac{v \varepsilon}{k}\right)^{3 / 4}, \quad C_{\xi}=2,1377 ; \quad \tau^{*}=C_{\tau}\left(\frac{v}{\varepsilon}\right)^{1 / 2}, \quad C_{\tau}=0,4082
$$

The net source of species $i$ by chemical reaction

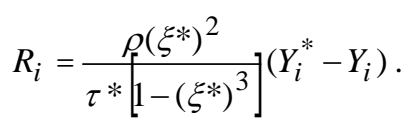

\section{Experimental Investigations}

Let's mark that during the basic vortex combustor (internal diameter $145 \mathrm{~mm}$ ) fire tests it turned out that the bottom part is the hottest combustor element ${ }^{6,8}$. Within the small-size triple vortex combustor engineering were found some innovative solutions for essential reduction of this part temperature (Fig. 3). According to test results for all investigated modes its walls temperature did not exceed $190{ }^{\circ} \mathrm{C}$ for low flow and was at the $90-100{ }^{\circ} \mathrm{C}$ level for medium to high flow rates.

Fig. 4 shows generalized dependences of nitrogen oxide emission on the combustor operation modes characterized by the air excess coefficient $\lambda$ for four basic fuel injection methods without electric discharge 


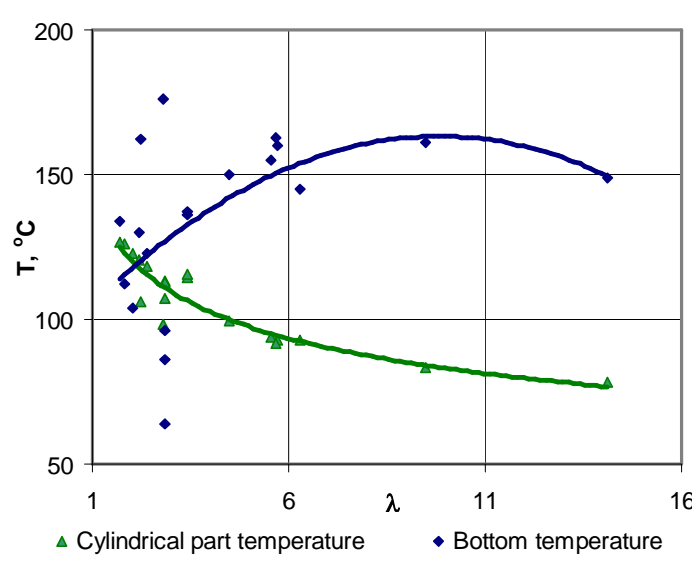

a)

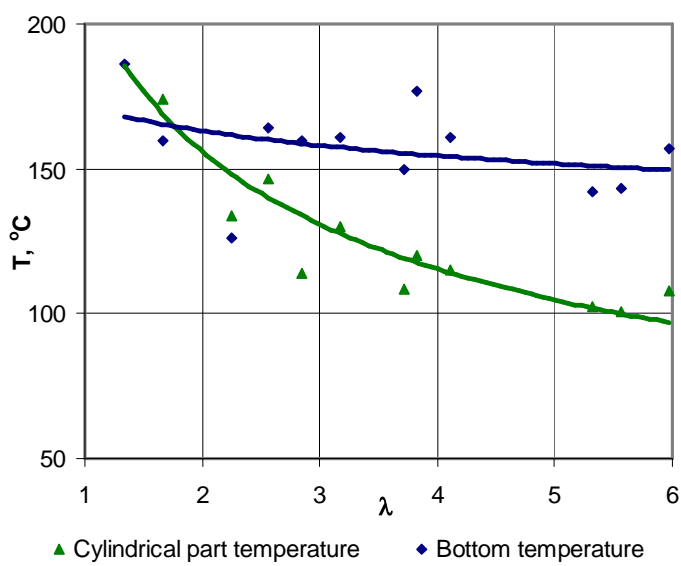

b)

Figure 3. Temperatures of triple vortex combustor elements: a) - plasma pilot, b) - central fuel atomizer.

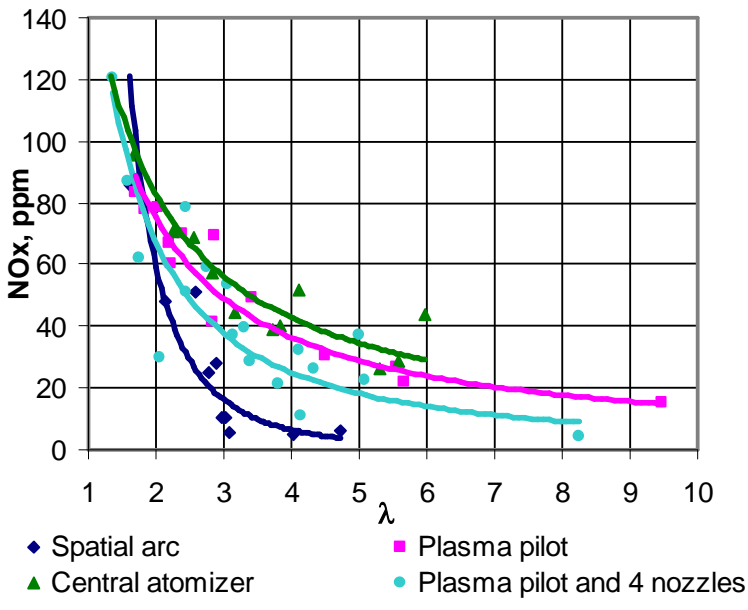

a)

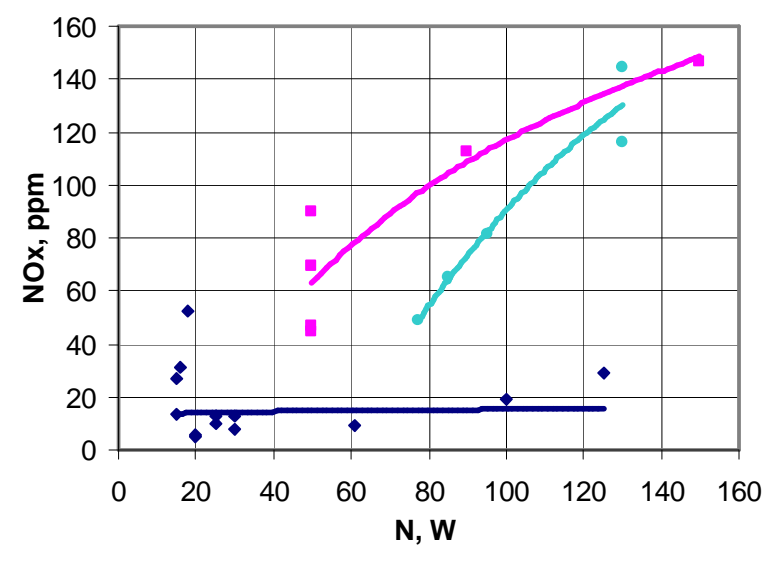

- Spatial arc - Plasma pilot - Plasma pilot and 4 nozzles

Figure 4. NOx concentration at the triple vortex combustor exit: a) - plasma is off, b) - plasma is on.

initiation (Fig. 4,a), and with plasma device operation (Fig. 4,b). $\mathrm{NO}_{\mathrm{x}}$ emission did not exceed 150 ppm for $\lambda$ varying from 1.5 to 9.5 and the tendency for its increase occurs with discharge power growth.

In Fig. 5 similar generalized dependences for $\mathrm{CO}$ emission are presented. Excitation of electric discharge in the plasma pilot results in $\mathrm{CO}$ concentration reduction in consequence of fuel oxidation reactions acceleration. With spatial arc burning inside the combustor its influence on $\mathrm{CO}$ afterburning is not so evident, and requires further experimental and theoretical investigations.

Let's note that some series of triple vortex combustor tests with emission control by TESTO-350 XL gas analyzer with low NOx and $\mathrm{CO}$ cells showed 1-2 ppm values for both $\mathrm{NO}_{\mathrm{x}}$ and $\mathrm{CO}$.

\section{Theoretical Investigations}

Interaction of the vortex flows of primary and plasma feedstock air (spreading along the cylindrical wall) causes very complicated aerodynamic flow structure inside the combustor. Some peculiarities of this structure for the total air excess coefficient $\lambda=3.42$, primary and plasma feedstock air flow rate 3.6 and $1.0 \mathrm{~g} / \mathrm{s}$ with fuel injection through four nozzles are shown in Fig. 6. In CFD calculations the RNG $k-\varepsilon$ model of turbulence and two-stage reaction of propane burning were used with taking into consideration influence of turbulent pulsations on kinetics 


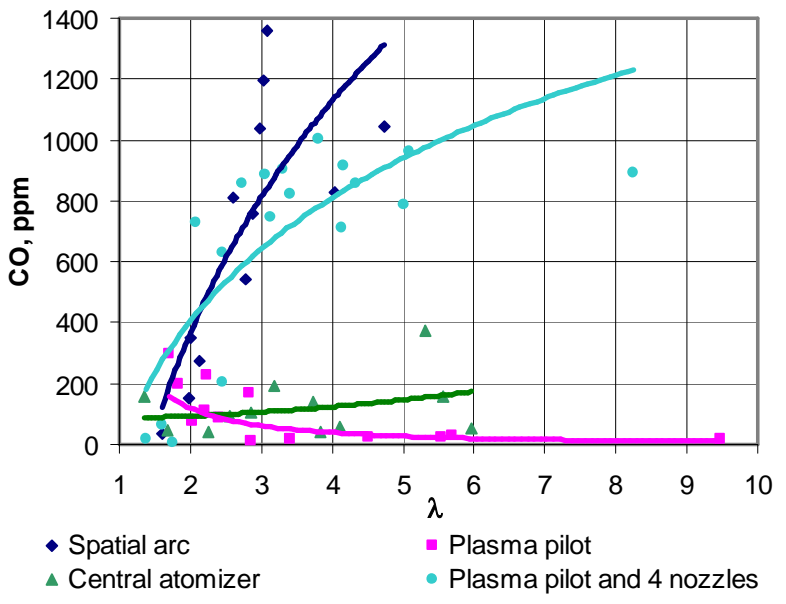

a)

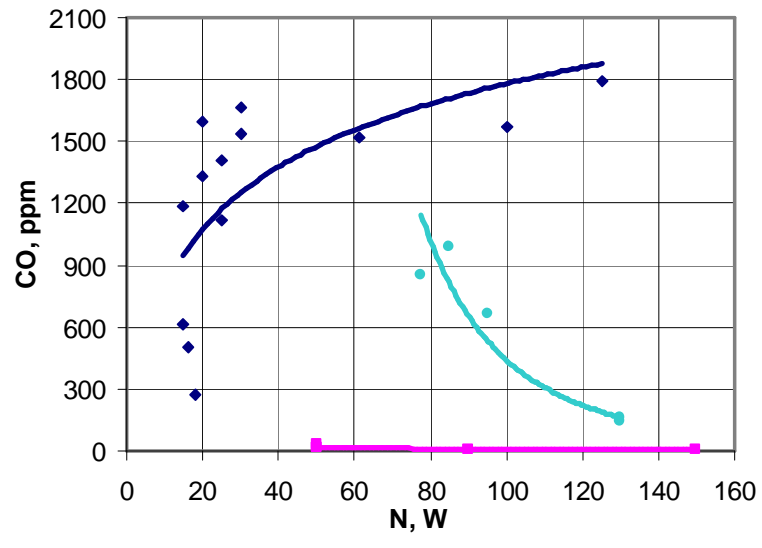

- Spatial arc - Plasma pilot - Plasma pilot and 4 nozzles

Figure 5. CO concentrations at triple vortex combustor exit:

a) - plasma devices are switched off, b) - plasma devices are switched on.

within the framework of Eddy Dissipation Concept and multi-component diffusion. It is important that the effective diameter of flame surface corresponds exactly to the exit nozzle diameter, and extension of the reverse flow zone in the combustor exit cross-sections is determined by primary air swirling intensity.
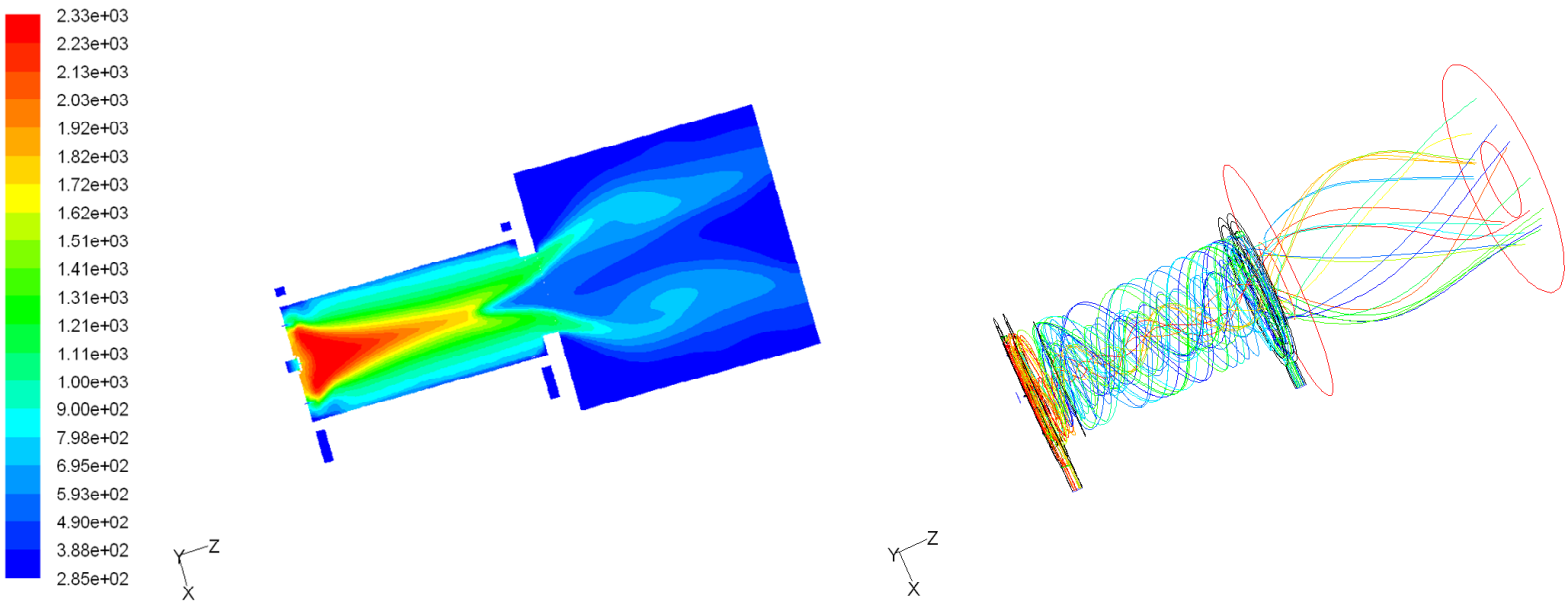

Figure 6. Calculated temperature distribution $(\mathrm{K})$ and path lines in the combustor with ID = $73 \mathrm{~mm}$.

For comparison of theoretical and experimental data numerical simulations of small-sized triple vortex combustor with plasma pilot located at the bottom combustor part are carried out. Operation conditions for triple vortex combustor test are the following: air mass flow rate through tangential swirler $15.53 \mathrm{~g} / \mathrm{s}$, air inlet temperature $318.5 \mathrm{~K}$, air mass flow rate through the DC plasma torch $0.666 \mathrm{~g} / \mathrm{s}$, temperature of plasma feedstock air $294.1 \mathrm{~K}$, propane mass flow rate through the plasma torch $0.155 \mathrm{~g} / \mathrm{s}$, propane inlet temperature $294.1 \mathrm{~K}$. During CFD calculations the RNG $k-\varepsilon$ turbulence model with swirl dominated flow, 3D pressure based solver, steady formulation, SIMPLE pressure-velocity coupling, simple eddy-dissipation combustion model of propane $\left(\mathrm{C}_{3} \mathrm{H}_{8}\right)$ are used. Note, that a special exhaust tube with $600 \mathrm{~mm}$ length have been adjusted to the exit combustor nozzle to avoid air injection from the atmosphere and combustion products dilution.

Fig. 7 shows the scheme of working fluids injection and the static temperature distribution in combustor volume. Note, that gaseous propane was injected into DC plasma torch channel together with plasma feedstock air. Therefore their preliminary mixing has been ensured. 


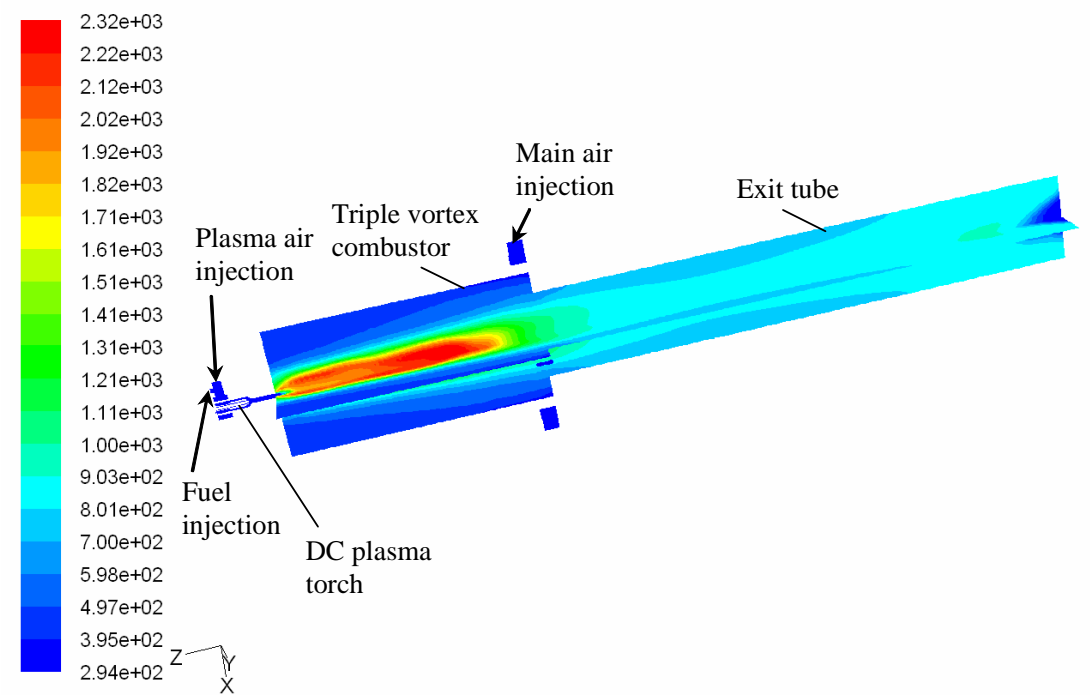

Figure 7. Contours of static temperature, $\mathrm{K}$.

The zone of maximum temperatures takes place in the central part of combustion chamber. Owing to influence of main swirling air the gas temperature is sharply diminished at combustor periphery regions, which confirms his excellent cooling properties. Despite the presence of the exit tube with $600 \mathrm{~mm}$ length the air leak-in at output crosssection takes place as a result of the significant centrifugal effect of main air.

Contours of mass fraction of $\mathrm{O}_{2}$ and $\mathrm{CO}$ are presented in Fig. 8. They confirm the high completeness of propane burning inside the combustor volume with minimum carbon oxide emission (Fig. 8,a) at these operation conditions, and also illustrate the considerable cooling effect of parietal air (Fig. 8,b).

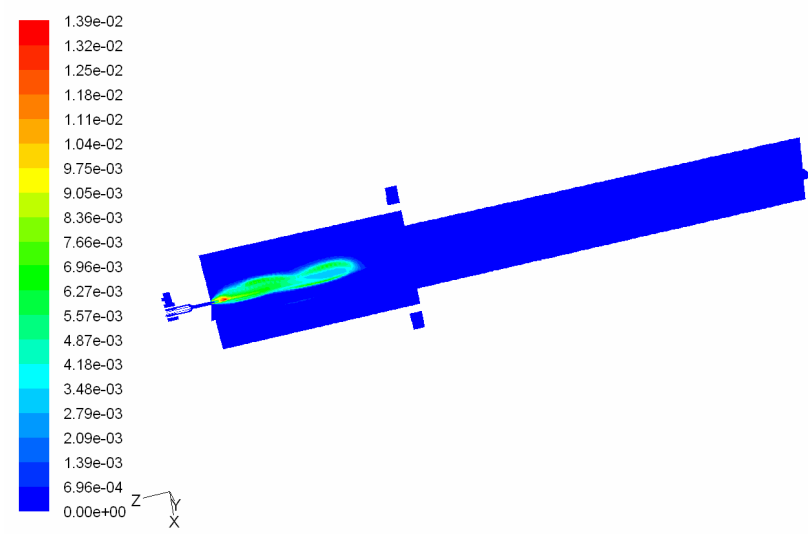

a)

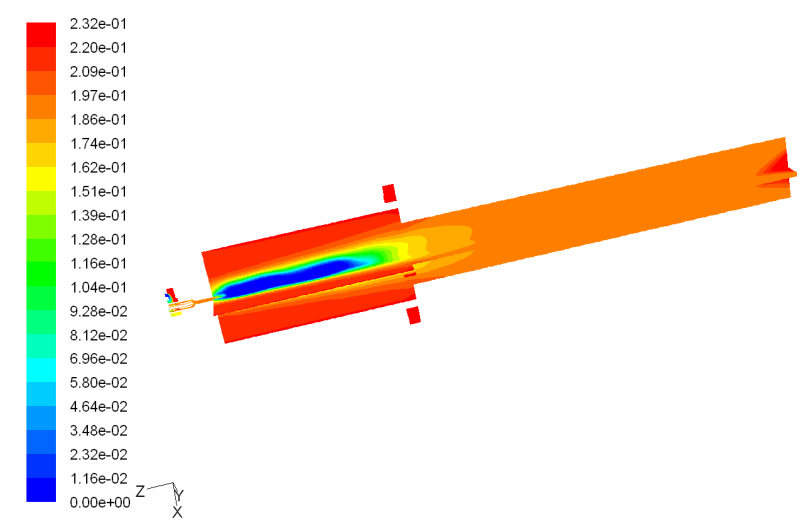

b)

Figure 8. Contours of mass fraction of $\mathrm{CO}$ (a) and $\mathrm{O}_{2}(\mathrm{~b})$.

Fig. 9 shows comparison of the actual and predicted (blue and green lines) radial gas temperature contours in two exit tube cross-sections located at the distance of 102 and $205 \mathrm{~mm}$ after triple vortex combustor nozzle. Actual temperatures have been measured simultaneously by five thermocouples located on radiuses $42,21,0,-21,-42$ $\mathrm{mm}$. Actual radial temperature contours have significant irregularity. It can be explained by non-uniformity of main air mass flow rate through vortex generator tangential channels. As a whole, conformity of experimental and numerical data is satisfactory, but more detailed many-stages chemical reacting mechanism is required for more accurate mathematical modeling. 


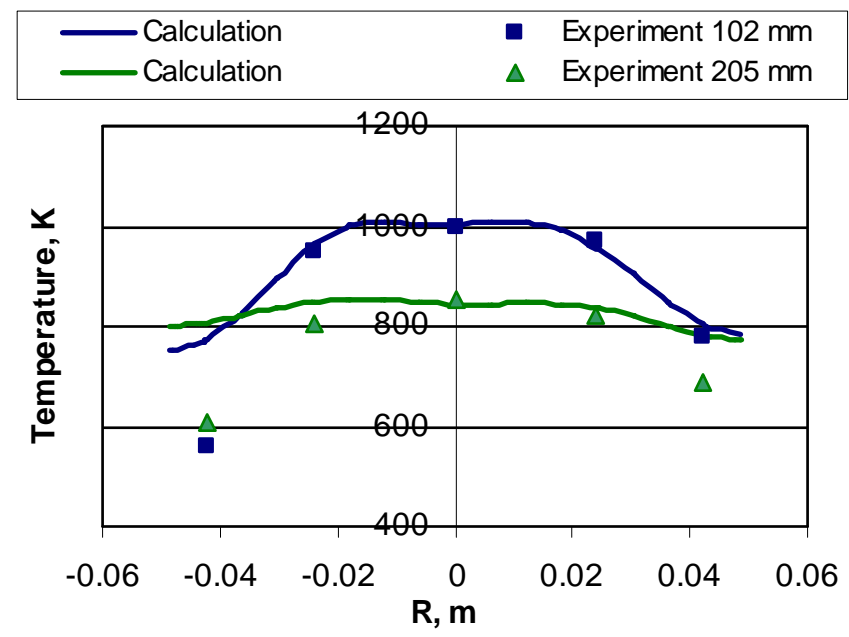

Figure 9. Radial contours of temperature in exit tube.

\section{Conclusion}

Above results show that selected for development and investigations concept of portable triple vortex combustor with plasma assistance can provide higher performance, wider turn down ratios, more efficient propellants utilization, provide reliable ignition and continuous energy efficient flame control without additional equipment, simpler design, cheaper materials, lower manufacturing costs, demonstrate potential fuel flexibility, satisfy major gravimetric and volumetric density requirements, etc.

\section{References}

${ }^{1}$ Lefebvre, A.Y., Gas Turbine Combustion, Hemisphere Publishing Corporation, New York, 1986.

${ }^{2}$ Poinsot, T., Veynante, D., Theoretical and Numerical Combustion, R.T. Edwards, Inc, Philadelphia, 2001.

${ }^{3}$ Zelina, J., Greenwood, R. T., Shouse, D. T., "Operability and efficiency performance of ultra-compact, high gravity (g) combustor concepts", 51th ASME International Gas Turbine and Aeroengine Congress and Exposition, 2006, Barcelona, Spain, GT2006-90119.

${ }^{4}$ Matveev, I., Applied Plasma Technologies, U.S. Patent Application for a “Triple Helical Flow Vortex Reactor”, 11/309644, filed 02 Sept., 2006.

${ }^{5}$ Matveev, I., Matveeva, S., Gutsol, A., Fridman, A., "Non-Equilibrium Plasma Igniters and Pilots for Aerospace Application", 43d AIAA Aerospace Sciences Meeting and Exhibit, 10- 13 January 2005, Reno, Nevada, AIAA-2005-1991.

${ }^{6}$ Matveev, I., Serbin, S., "Experimental and Numerical Definition of the Reverse Vortex Combustor Parameters", 44th AIAA Aerospace Sciences Meeting and Exhibit, 9-12 January 2006, Reno, Nevada, AIAA-2006-0551.

${ }^{7}$ Www.plasmacombustion.com

${ }^{8}$ Matveev, I., Serbin, S., Butcher, T., Tutu, N., "Flow Structure investigation in a "Tornado" Combustor", 4th International Energy Conversion Engineering Conference and Exhibit (IECEC), 26-29 June 2006, San Diego, California, AIAA $2006-4141$.

${ }^{9}$ Matveev, I., Serbin, S., Mostipanenko, A., "Numerical Optimization of the "Tornado" Combustor Aerodynamic Parameters", 45th AIAA Aerospace Sciences Meeting and Exhibit, 8-11 January 2007, Reno, Nevada, AIAA 2007-391.

${ }^{10}$ Serbin, S.I., "Modeling and Experimental Study of Operation Process in a Gas Turbine Combustor with a Plasma-Chemical Element", Combustion Science and Technology, Vol.139, 1998.

${ }^{11}$ Batchelor, G. K., An Introduction to Fluid Dynamics, Cambridge Univ. Press, Cambridge, England, 1967.

${ }^{12}$ Launder B. E., Spalding D. B., Lectures in Mathematical Models of Turbulence. Academic Press, London, 1972.

${ }^{13}$ Spalding D.B., "Mathematical Models of Turbulent Flames: A Review", Combustion Science and Technology, 1976, Vol. 1

${ }^{14}$ Choudhury, D., "Introduction to the Renormalization Group Method and Turbulence Modeling", Fluent Inc. Technical Memorandum TM-107, 1993. 